\title{
O IMPACTO SOCIAL DAS IMAGENS E REPRESENTACÕES DO TRADUTOR NA CONSTRUÇÃO E TRANSFORMAÇÃO DE SUA IDENTIDADE
}

\author{
Leila Cristina de Mello Darin*
}

\begin{abstract}
RESUMO: O presente artigo pretende discutir a questão da identidade do tradutor, a fim de contribuir para uma percepção mais aguçada da imagem que tem de si esse profissional e de como ela é criada e mantida. O alicerce teórico para a discussão sobre a formação de identidades é extraído de Stuart Hall, Tomaz da Silva e Kathryn Woodward. São sucintamente apresentados e debatidos textos que tratam da identidade do tradutor, analisandoa a partir do discurso dos próprios profissionais da área e de estudiosos, críticos e resenhistas (Lages, Coracini, Arrojo, Sette, Silva, Pomarico, Teixeira). As representações apontam para uma identidade híbrida, mutável, repleta de tensões e visões conflitantes. Segue-se uma reflexão sobre os aspectos ideológicos que matizam as representações do tradutor e avalia-se a estratégia de identificação com o autor. Discutem-se algumas formas de lidar com a imagem com frequência negativa que os tradutores reforçam em seu discurso.
\end{abstract}

PALAVRAS-CHAVE: Identidade; Tradutor; Ideologia; Imagem social.

ABSTRACT: This article aims to discuss the identity of the translator in an attempt to enhance the perception of how translators see themselves and how this image is created

\footnotetext{
* Profa. Dra. Pontifícia Universidade Católica de São Paulo.
} 
and maintained. The theoretical foundation used for the discussion on identity construction is taken from Stuart Hall, Tomaz da Silva and Kathryn Woodward. Texts on the translator's identity, which analyze the discourse of translation professionals and theorists, critics and reviewers, are briefly presented and discussed (Lages, Coracini, Arrojo, Sette, Silva, Pomarico, Teixeira). The representations point to a hybrid, multiple identity, marked by tensions and conflicting views. Considerations on the ideological aspects that permeate the translator's representations are presented and the strategy of using the identity of the author as a reference for the translator's identity is examined. Ways of dealing with the oftentimes negative image that translators themselves emphasize in their discourse are discussed.

KEYWORDS: Identity; Translator; Ideology; Social image.

O que são as numerosas traduções da Ilíada, de Chapman a Magnien, senão perspectivas variadas de um fato móvel, senão um grande sorteio de omissões e de ênfases? (Jorge L. Borges)

\section{Introdução}

No atual contexto sociopolítico-tecnológico de grandes mudanças e incertezas, somos levados a indagar quem somos e a perceber criticamente aquilo que, no mundo contemporâneo, nos constitui e define. Não é de surpreender, portanto, que o tema da identidade tenha merecido a atenção de estudos nas áreas de Ciências Humanas e Ciências Sociais, nos convidando a ponderar sobre os processos de construção e manutenção das representações que nos significam e que significam nossas relações.

Refletir sobre a constituição de identidades implica, também, pensar sobre a própria constituição do humano. Afinal, quem são e como se formam estes sujeitos que nos habitam e nos definem para os outros e para nós mesmos? Em que se ba-

TradTerm, 16, 2010, p. 67-95 
seiam as autodefinições e que poder (ou responsabilidade) temos sobre sua confecção e continuidade? No âmbito profissional, que fatores contribuem para a criação de determinados estereótipos, imagens, representações e "verdades"?

\section{Identidade: caráter do que é exclusivo ou próprio de uma pessoa ou grupo}

A mutabilidade e precariedade de toda definição - incluindo a do subtítulo acima - tem se constituído tema de filósofos e estudiosos em busca de aprofundar o conhecimento sobre a natureza do ser e seu lugar no mundo. Embora as restrições a que estão sujeitas as definições pareçam ser bastante conhecidas, seja por motivos práticos, políticos ou culturais, acabamos por aprisionar ideias, sentimentos, sensações e experiências em sinteses autoexplicativas, na ilusão de que possam garantir a nossos destinatários (e a nós) a estabilidade dos sentidos pretendidos.

Se acompanharmos o percurso histórico da noção de identidade - tema que aqui nos interessa - constataremos que sua plasticidade e complexidade acompanham a história do pensamento humano, retratando tanto suas limitações quanto seu vasto potencial. Stuart Hall, professor e pesquisador da área de Estudos Sociais, em seu livro A identidade cultural na pós-modernidade, de1992, apresenta as principais mudanças pelas quais passou a concepção de identidade, centrando-se em três perspectivas, decorrentes, respectivamente, da visão dos sujeitos Iluminista, Sociológico e Pós-moderno.

Ciente dos limites de sua classificação, Hall propõe uma análise que evidencia o caráter provisório e mutante da noção de identidade. Assim, seu ponto de partida é a concepção de "eu" do sujeito Iluminista como um "indivíduo totalmente centrado, unificado, dotado das capacidades de razão, de consciência e de ação, cujo 'centro' consistia num núcleo interior" (Hall, 2005:10); tal núcleo, que se acreditava inerente ao sujeito, permanecia "idêntico" ao longo de sua vida, constituindo-se na essência da pessoa, na sua identidade.

A história e a cultura do final do século XIX e da primeira metade do século XX - com sua ênfase na coletividade e no mo- 
delo de democracia - produziram uma mudança na concepção de sujeito, que passou a ver visto como produto de sua interação com a sociedade. As novas Ciências Sociais, em particular a Sociologia, definiam os individuos com base em sua participação nos processos e estruturas mais amplos, dentro dos quais assumem diversos papéis sociais. A identidade desse sujeito moderno é produto do diálogo que o indivíduo trava com o coletivo - diálogo contínuo que "costura (ou, para usar a metáfora médica, 'sutura') o sujeito à estrutura" (Hall, 2005:12).

A partir da segunda metade do século XX, ocorre um verdadeiro abalo nas concepções vigentes de identidade, decorrente da chamada "modernidade tardia" ou "pós-modernidade" ligada, como bem resume Hall, a cinco grandes avanços nas ciências sociais, a saber: 1) a reinterpretação do pensamento marxista e a rejeição de uma essência universal do homem; 2) o desenvolvimento da teoria freudiana, a qual "arrasa com o conceito do sujeito cognoscente e racional provido de uma identidade fixa e unificada" (Hall, 2005:36); 3) a releitura derridiana de Saussure, que enfatiza a instabilidade a que estão sujeitos os significados, a partir do processo infinito de diferenciação; 4) a ideia do "poder disciplinar" de M. Foucault, exercido pelas instituições administrativas que visam controlar, vigiar e punir os indivíduos "para o bem comum"; 5) os movimentos sociais, especialmente o feminismo, que criaram politicas próprias de identidade, uma para cada movimento, desestabilizando e multiplicando as identidades (idem: 34-46).

Hoje, no mundo contemporâneo, vivemos os efeitos e consequências dessas "rupturas" que requalificam a noção de identidade como hibridismo, heterogeneidade e descentramento. Dada sua importância para nosso argumento, gostaríamos de nos deter muito brevemente em dois dos cinco descentramentos apontados por Hall.

\subsection{O outro e eu: "diga-me espelho meu..."}

O conceito de inconsciente como parte integrante do "eu", e, portanto, a revelação de que a consciência responde apenas por uma parte do indivíduo (Freud, 1899), redirecionou o con-

TradTerm, 16, 2010, p. 67-95 
ceito de identidade do sujeito racional de forma contundente. A leitura da teoria freudiana empreendida por J. Lacan não é menos impactante: nosso "eu" é uma imagem apre(e)ndida gradualmente à custa de negociações inconscientes contínuas e complexas. Lacan (1966) postula que no processo de formação identitário, a criança (entre 6 e 18 meses) constrói sua autoimagem a partir do seu outro, refletido no espelho, aquele no qual enxerga a si mesma. Essa percepção representa o momento em que são geradas as noções imaginárias de eu-ideal e ideal-deeu que formam a base de suas relações com o mundo. Essa matriz ou molde do "eu" é a referência para a construção e elaboração da identidade de cada ser humano ao longo de sua existência, em resposta às inúmeras solicitações da vida social e cultural.

A relevância dessa concepção de identidade é que, ao mesmo tempo em que afirma a natureza da autodefinição do sujeito como impalpável, subjetiva e dependente "do outro", ela possibilita, àquele que vê a imagem "inteira" refletida no espelho, a ilusão de unidade e estabilidade, como se o conjunto de atributos e sensações registradas na rasa superficie de vidro lhe garantisse a certeza de existir como um ser singular e autossuficiente.

Os estudos de Lacan abrigam e acolhem as contradições, os papéis conflitantes, as máscaras e oscilações de um ser múltiplo, cuja identidade se constitui sempre e necessariamente a partir da alteridade. Como constata com muita clareza Miriam Chnaiderman ao discorrer sobre a obra lacaniana, "é o olhar do outro que permite a constituição de uma imagem unitária. Surge um eu sempre mediado pela relação com um outro. O sujeito se vê como é visto por seus semelhantes. É essa a alienação fundante do sujeito psíquico" (Chnaiderman, 2002:54). Ou ainda, como afirma a psicanalista: "é no espaço do Outro que se situa o ponto de onde o sujeito se olha" (idem: 55 ).

\subsection{Waiting for Godot}

A percepção saussuriana de que a língua é um sistema de diferenças inspirou muitos estudiosos; dentre eles, destaco a linha de questionamento do filósofo francês Jacques Derrida. Se 
um signo, conforme argumentou Saussure (1916), ganha valor e significação no interior do sistema linguístico ao qual pertence a partir das semelhanças e diferenças que estabelece com outros signos, então, conclui Derrida (1967), o signo não é uma presença, mas um adiamento, uma diferença, um traço que posterga indefinidamente o sentido absoluto, concreto, final. Como adquirem significado a partir da rede de relações dos sistemas linguísticos, os signos não gozam de uma interpretação única $\mathrm{e}$ autocentrada. Sobrevivem na sua diferença, motivo pelo qual não podem ser reduzidos a uma identidade cerrada, autorreferente.

Assim, segundo Derrida, e em sintonia com o pensamento lacaniano, o signo identidade só pode ser entendido por meio de espelhamento; isto é, se considerarmos como parte de sua constituição os outros signos que dele diferem, se aproximam e se somam, e que tornam sua imagem "visivel" e possivel. Ser professor é não ser aluno, diretor, pai, terapeuta, colega de classe e é, ao mesmo tempo e em alguma medida, ser todos eles, aos quais o professor "deve" sua identidade. Isso implica que a identidade não é compreendida como um "idêntico a si" e não pode ser definida com referência ao "eu" autônomo; ela é, antes, um conjunto híbrido de traços diferenciais que jamais pode ser fixado de forma definitiva. Aqui recorremos novamente à reflexão de Chnaiderman para reforçar a proximidade da ideia derridiana do ponto de vista lacaniano: "o sujeito, para Lacan, é um significante que remete a outro significante, ou um significante é o que representa o sujeito para outro significante" (Chnaiderman, 2002:55).

A determinação do signo com base no significante e na diferença tem implicações politicas e ideológicas vitais. Conforme argumenta Derrida, no jogo da diferenciação, algumas palavras são privilegiadas pelos discursos que estruturam determinada cultura e sociedade, ao passo que outras são negativamente valoradas. Ao criarmos uma identidade, pela recusa e negação do que dela difere, geramos simultaneamente uma relação de inclusão (o positivo, o centro, a norma) e exclusão (o negativo, a margem, o desvio). Tomás Tadeu da Silva, ao refletir sobre a questão do poder postulada pelo filósofo francês, esclarece:

TradTerm, 16, 2010, p. 67-95 
Fixar uma determinada identidade como a norma é uma das formas privilegiadas de hierarquização das identidades e das diferenças. (...) Normalizar significa eleger - arbitrariamente - uma identidade específica como o parâmetro em relação ao qual as outras identidades são avaliadas e hierarquizadas. Normalizar significa atribuir a essa identidade todas as características positivas possíveis, em relação às quais as outras identidades só podem ser avaliadas de forma negativa. A identidade normal é "natural", desejável, única. A força da identidade normal é tal que ela nem sequer é vista como uma identidade, mas simplesmente como a identidade. (...) Numa sociedade em que impera a supremacia branca, por exemplo, 'ser branco' não é considerado uma identidade étnica ou racial. (Silva, 2005:83, grifos do autor)

Em outras palavras, identificar é optar por favorecer certos aspectos em detrimento de outros. Tal processo de favorecimento de sentidos, argumenta Derrida, dá-se pela incansável reiteração dos conceitos privilegiados, pela inculcação de valores que passam a ser aceitos como verdadeiros. A repetição de "verdades", desse modo, serve à imposição e fixação de visões de mundo que interessam às instâncias de poder, desde a mais abrangente a mais sutil.

Essas considerações incitam indagações fundamentais para nosso trabalho. Se a identidade é um complexo de traços diferenciais, quais deles constituem a identidade do tradutor profissional? Que imagens e representações atravessam o discurso de tradutores, estudantes de tradução, críticos, leitores e leigos? Onde essas ideias e ideais se encontram; quando se distanciam? Que contradições abrigam as auto-representações de tradutores? Como é fixada e reiterada a identidade do tradutor? É possivel transformar tal visão?

\section{3. "Aquele que conduz além": 'aquele' quem, conduz o quê, para além-onde?}

Ao longo da história, a tradução tem sido alvo de uma série de polêmicas e posições defendidas com paixão, registradas 
em documentos, paratextos, relatos informais, mitos e nas criações humanas em geral. Da maldição bíblica de Babel sentenciada por Deus ${ }^{1}$ à tradução automática, são incontáveis as avaliações que enfatizam ora o fracasso da atividade tradutória e seu resultado inferior e precário, ora a nobreza de sua missão e seu inestimável valor social. A criação de estereótipos positivos ou negativos sobre a figura do tradutor parte de escritores, críticos literários, filósofos e estudiosos da linguagem, leitores de traduções e dos próprios tradutores.

Em função da grande quantidade de dados sobre a figura do tradutor - lembremos que as primeiras traduções, feitas do sumério para o acádio, datam de séculos antes de Cristo (Albir, 2001:100) -, optamos por restringir nosso olhar para as pesquisas recentes que se propõem investigar as imagens do tradutor, especialmente no contexto brasileiro. Isso não quer dizer que levaremos em conta apenas o contexto contemporâneo; mesmo porque acreditamos que cada momento histórico retrata uma tendência, um padrão geral que, examinado de perto, constitui uma amálgama de criações, fatos e ideologias passados, presentes e potencialmente futuros, que convivem de forma dinâmica e inter-relacionada.

O ponto de partida é o artigo "O tradutor e a melancolia" de Susana Lages, publicado no volume 19 do periódico Trabalhos em Lingüistica Aplicada (1992). O texto de Lages oferece uma análise das visões de tradutores, escritores e teóricos a respeito da tradução, pelo viés da Psicanálise. Seu argumento central é o de que o exame das imagens tradicionais e mais difundidas do tradutor revela ora um discurso marcado pela melancolia e por uma profunda tristeza, ora uma idealização da figura do tradutor, entendida como tendência à mania (euforia), tendência essa oposta e complementar à melancolia. Entre "rebaixamentos e auto-reproches" (Lages, 1992:92) e a postura "heroica, onipotente" (idem: 93), a identidade do tradutor - e aqui a ênfase é no tradutor literário -, assume uma ambivalência.

"Por isso deram-lhe o nome de Babel, porque ali o Senhor confundiu a linguagem de todos os habitantes da Terra, e dali os dispersou sobre a face de toda a Terra" (Gênese, 11, v. 1-9).

TradTerm, 16, 2010, p. 67-95 
Lages relaciona essa "bipolaridade" à expectativa de que a tradução seja fiel ao texto dito original, isto é, que ela promova o total resgate das intenções, conteúdos e conotações da obra literária a ser traduzida. Assim, o tradutor passa a ser visto, inclusive por si mesmo, como aquele a quem é dado o poder de realizar uma tarefa igual em valor à do escritor (onipotência) e, ao mesmo tempo, como aquele que jamais logra de fato atingir essa meta (impotência). A impossibilidade de recuperar todos os sentidos inscritos no texto original gera, para o tradutor, um estado de melancolia, dor e frustração. As palavras de G. Steiner (1976), citadas por Lages, reforçam essa visão:

Mas o 'milagre' nunca é total. Toda tradução fracassa em algum sentido. No melhor dos casos, escreveu Huet, a tradução pode, por meio de autocorreções cumulativas, acercar-se dos imperativos do texto original, traçando tangentes cada vez mais próximas. Mas jamais chega à total circunscrição. Da percepção da eterna inadequação emerge uma certa tristeza, que ameaça a história e a teoria da tradução. (...) Há um infortúnio/ mal/ sofrimento único na tradução, uma melancolia pós-Babel. (Steiner apud Lages, 1992:96)

Tal representação do tradutor é criticada por Lages ao final de seu artigo, quando a autora afirma que a entende como "total descaso para com a figura do tradutor enquanto sujeito do processo da tradução" (Lages, 1992:97). São muitos os estudiosos que, como Lages, desafiam essa visão de tradução, colocando o tradutor como ator de um processo de interpretação que implica a produção de um outro/mesmo texto para outra comunidade cultural.

Muito embora a revisão de conceitos centrais à tradução tenha provocado, nas últimas décadas, modificações no papel e na imagem do tradutor, pesquisadores que se detêm especificamente na questão identitária constatam que ainda perduram visões estereotipadas, calcadas em noções consagradas pela reiteração e repetição. Vejamos o que dizem alguns deles. 


\section{Ilusões de ótica: reflexos, refrações, miragens}

Dois artigos produzidos pela $\operatorname{Prof}^{\mathrm{a}} \operatorname{Dr}^{\mathrm{a}}$ Maria José Coracini, docente da Unicamp, oferecem reflexões que dão continuidade à discussão levantada por Lages em 1992. Ambos abordam a identidade do tradutor pelo olhar da Psicanálise e da Desconstrução.

Em "(Auto-) Representações do tradutor: entre a fidelidade e a traição" (2005a), Coracini detém-se na autoimagem do tradutor, baseando sua pesquisa na coletânea de entrevistas Conversa com Tradutores (Benedetti \& Sobral, 2003). Partindo do conceito de identidade pela perspectiva psicanalitica, qual seja, "como resultante de um conjunto de imagens ou representações que conferem ao sujeito a ilusão ou o sentimento (Berry, 1992) de estabilidade e unidade" (Coracini, 2005a:92), ela extrai dos discursos dos tradutores cinco representações que conferem a eles a "ilusão" de identidade:

- traduzir é ser fiel (desejo de reproduzir a intenção do autor);

- traduzir é sentir prazer (satisfação pela atividade intelectual);

- ser tradutor é ser ponte (elo de comunicação entre dois mundos);

- ser tradutor é ser um grande conhecedor (dos idiomas, das culturas, da vida);

- ser tradutor é estar entre (duas ou mais) línguas.

Em sua análise das imagens acima, a pesquisadora interpreta que a insistência em ressaltar aspectos que engrandecem a tradução e o tradutor decorre da desvalorização de ambos. Por isso, a autora vê nesse conjunto de representações uma identidade híbrida, que oscila entre a demanda da realização de uma grande missão (completude) e a inviabilidade desse projeto (falta). Assim dividido, o tradutor vive a angústia de estar "entre", encarcerado pelos limites e possibilidades das línguas, das culturas e da expressão das individualidades. Isso a leva a concluir que:

O tempo todo o tradutor se mostra servil, submisso, escravo, inferior ou secundário: a serviço do autor do texto

TradTerm, 16, 2010, p. 67-95 
de partida, do significado que estaria arraigado às palavras e ao qual acredita dever fidelidade, dever no sentido de contrair uma divida e não conseguir pagar. (Coracini, 2005a:106-7)

Muitas das afirmações de Coracini foram corroboradas por uma pesquisa de Iniciação Científica desenvolvida ao longo de 2006, sob minha orientação, realizada pelo então graduando João Risoli da Silva. Seu objetivo era o estudo da imagem que tem de si o tradutor a partir das próprias declarações sobre seu trabalho a partir da coletânea de entrevistas Conversa com Tradutores (2003) e de textos colhidos na Internet. Da pesquisa, emergiram as seguintes imagens, assim denominadas por Risoli:

- "O traidor" - imagem ligada à fidelidade, à soberania do texto de partida e do autor. O tradutor divide-se entre a exigência e a impossibilidade de ser "fiel".

- "Poderes mágicos" - representação do tradutor com o superpoder da invisibilidade, como resposta à expectativa de que sua ação seja neutra e seu papel, "modesto".

- "Tower Bridge ou Ponte de Londres" - imagem bastante comum que alude à tarefa do tradutor como mera passagem de um ponto a outro.

- "Faço, logo existo" - relação que o tradutor mantém com seu trabalho - fonte de prazer pela tradução bem feita -, e de tristeza, pelas limitações impostas.

- "Quando 2 + 2 não são 4" - autoimagem do profissional, chamado a justificar as escolhas perante leitores, autores, críticos, espectadores, falantes bilingues. Sofre as consequências da falta de regulamentação da profissão.

- "O sexto sentido" - o tradutor não é "não tão bom" como o autor, mas possui "dons pessoais": inteligência, talento, "persistência, observância à disciplina, preciosismo na comunicação, acuidade em relação aos detalhes, olhar alerta e observador, sempre!" (Risoli, 2007:55).

Como se pode observar, as imagens levantadas por Silva (2007) e por Coracini (2005a) são bastante próximas, revelando 
as contradições que existem no discurso de tradutores, estudiosos ou críticos quando discorrem sobre "quem é" esse profissional e o que se espera de seu trabalho. As cobranças chegam a ser desproporcionais, levando a duas percepções opostas: a de ser merecedor de crédito e a de estar eternamente em débito.

Em outro texto sobre o mesmo tema, "Discurso sobre a tradução: aspectos da configuração identitária do tradutor", Coracini (2005b) examina artigos publicados no Brasil em periódicos científicos para verificar as representações de especialistas e teóricos da tradução. Seu pressuposto é o de que as autorrepresentações do tradutor constituem material para que especialistas construam imagens a seu respeito as quais, por sua vez, influenciam o imaginário do próprio tradutor, interferindo em sua configuração identitária.

Coerente com sua posição teórica, Coracini parte da noção de identidade como aquilo que "o sujeito é capaz de dizer (narrar) sobre si” (Coracini, 2005b:34) e que se constrói necessariamente a partir da relação com o outro, no desejo de corresponder ao outro. "Tomamos, portanto, a identidade como uma construção imaginária ou uma soma de construções imaginárias sempre a partir do outro, do discurso-outro" (idem: 36, grifos do autor).

Com seu olhar instigante, a pesquisadora conclui que o sujeito tradutor constrói sua identidade com base numa rede de representações constituída por fragmentos de discursos de outros sujeitos e pelo seu próprio discurso. Assim, o tradutor é um sujeito "heterogeneamente constituído" (Coracini, 2005b:29) por múltiplas e conflitantes representações que resultam de sua experiência e de discursos os quais, por partirem de autoridades legitimadas pelas instâncias de poder, são internalizados. Tal sujeito, que habita a "região de conflitos entre o desejo de fidelidade e de reverência ao autor do texto-base e o desejo de ser o lugar da origem, de ser completo" (idem: 47), apresenta as seguintes contradições:

- Criação versus respeito e fidelidade ao autor/texto;

- Conhecimento das línguas versus impossibilidade de expressão plena;

TradTerm, 16, 2010, p. 67-95 
- Desejo de controlar sentidos versus alvo constante de críticas;

- Busca da invisibilidade versus presença inevitável (nas escolhas singulares);

- Conforto da determinação versus contingência desconfortável da indeterminação;

- Requisito da invisibilidade versus necessidade de reconhecimento social;

- Língua materna versus língua do outro.

De fato, essas imagens constituem um conjunto de atributos de valor que abrigam demandas, desejos e expectativas que se sobrepõem e contrapõem, formando uma figura multifacetada, apenas ilusoriamente homogênea.

Como se pode observar, a recorrência das representações nesses trabalhos aponta para um complexo identitário dinâmico, configurado a partir de dados e intuições advindos tanto da relação do tradutor com seu oficio quanto da avaliação de seu papel social, produto das expectativas, discursos e respostas do outro.

\section{A melancolia revisitada: outros caminhos}

Vimos que em "O tradutor e a melancolia", Susana Lages (1992) define a identidade predominante do tradutor como melancólica, referindo-se à bipolaridade psíquica que se caracteriza pela oscilação da mania à melancolia. De fato, em trabalhos dedicados à questão, Coracini explicita as vozes conflitantes que constroem o discurso do tradutor a respeito de sua identidade profissional, mostrando um sujeito dividido entre a angústia de ser fiel ao autor e o desejo de ocupar esse lugar de origem.

Dez anos após o trabalho de Lages, Maria de Lourdes Sette propõe-se a investigar se a imagem do tradutor melancólico ainda se sustenta diante das mudanças trazidas pela visão desconstrutivista abraçada por muitos teóricos da tradução e veiculada pela mídia impressa. Sua dissertação de mestrado intitulada $A$ identidade (ainda melancólica?) do tradutor - uma análise desses profissionais no Brasil na década de 90 a autora parte da seguinte indagação: 


\begin{abstract}
A identidade do tradutor que vem prevalecendo em todo o mundo há tantos séculos - e que se constitui como uma imagem acentuadamente negativa desse profissional e de seu ofício - já foi enfraquecida ou mesmo substituída pelos próprios tradutores, tal como o fizeram os estudiosos da tradução em decorrência de sua forte adesão ao pósestruturalismo? (Sette, 2002:06)
\end{abstract}

Sette cita várias imagens que, ao longo da história, desvalorizam o tradutor e empobrecem seu ego: pouco prestígio, infidelidade, traição, desvalorização, perdas. Essas imagens, aliadas a exigências desmedidas de conhecimento e talento, conduzem a metáforas depreciativas que reforçam sua baixa autoestima e a sensação de incapacidade para exercer sua atividade, "mantendo-o em uma atitude que Susana Lages, tradutora e estudiosa da tradução, denominou 'melancólica"' (Sette, 2002:13).

Preocupada com a representação negativa do tradutor, e a partir da revisão de base desconstrutivista dos pressupostos subjacentes a tal perfil, o objetivo de Sette em sua dissertação é contribuir para a mudança de atitude do tradutor e de seu discurso em relação à imagem que tem de si e da tradução.

Para tratar da questão da identidade, Sette apoia suas considerações nas ideias de pensadores dos Estudos Culturais, como Hall (1996), Woodward (1997), Giddens (1999) e Silva (2000); na revisão conceitual empreendida pelo pensamento desconstrutivista (Arrojo, 1986); e na concepção de "identificação" de Freud (1921) "como fenômeno que faz parte do processo estruturador de constituição e diferenciação do ego" (Sette, 2002:39). Com base nesses alicerces, a pesquisadora produz um discurso claro e coerente.

Por meio de entrevistas com tradutores literários ${ }^{2}$ e com resenhistas de obras traduzidas (por vezes também tradutores), Sette levanta e analisa as representações do tradutor, procuran-

2 Sette adota uma definição de tradução literária mais ampla, citando L. Venuti: "Darei ênfase à tradução literária entendida em um sentido amplo, principalmente poesia e ficção, mas também incluindo biografia, história e filosofia, entre outros gêneros e disciplinas das ciências humanas" (Sette, 2002:21).

TradTerm, 16, 2010, p. 67-95 
do observar se tendem à visão logocêntrica e essencialista (identidade como conjunto de características estáveis, imunes à ação tempo) ou à perspectiva pós-estruturalista e não-essencialista (identidade como conjunto fluido, passivel de mudança). A visão endossada pela pesquisadora é a não essencialista ou construcionista, segundo a qual as identidades estão em permanente estado de reconstrução.

Dentre as representações constatadas, Sette considera os seguintes temas:

- Prestígio e remuneração. O problema não é a remuneração, mas a falta de prestígio e de reconhecimento de um trabalho intelectual complexo;

- Tradutor versus autor. O tradutor mostra o desejo de identificar-se com o autor, para que possa representá-lo fielmente;

- Fluência/transparência versus estranheza. Trata-se da exigência de que o tradutor seja invisivel e reproduza a ilusão de presença autoral;

- Autodesvalorização. É a manifestação explícita da identidade melancólica, do complexo de inferioridade diante de um trabalho que nunca está perfeito;

- Fidelidade versus traição. Ideia de que a fidelidade total é a meta a ser atingida e que a "traição", ou desvio, é resultado da incapacidade do tradutor;

- Formação instrucional: necessária ou supérflua. Tema polêmico entre os respondentes, ligado à não regulamentação da profissão de tradutor.

Em sua discussão, a pesquisadora considera ser vital para a construção de uma nova identidade não melancólica e mais positiva a diferenciação entre o que é ser tradutor e o que é ser autor. De fato, pode-se argumentar que todos os temas citados estão ligados à forma como se interpreta a relação autor-tradutor, ou texto-tradução; é do entendimento dessa relação que são gerados julgamentos de prestígio ou autodesvalorização, de transparência ou visibilidade, de fidelidade ou traição e de identidade profissional. 
O prisma sob o qual se concebe a dinâmica autor-tradutor tem consequências vitais para a identidade desse último. A visão "tradicional" relega ao tradutor um status inferior ao do escritor, com base na convicção de que ele nada cria, apenas procura, na maioria das vezes sem muito sucesso, reproduzir em outro idioma aquilo que autor e obra dizem. L. Venuti, tradutor e teórico, resume essa posição com clareza ao afirmar que o conceito de autoria sugere originalidade ao passo que a tradução é derivada e provoca o medo da inautenticidade, da distorção (Venutti, 2002:65).

Essa perspectiva conduz à crença de que quem traduz é menos, pois é incapaz de recuperar integralmente o texto de partida, motivo pelo qual não tem qualidades que permitam que seu trabalho seja socialmente reconhecido.

Em contraposição a essa postura, outra forma de conceber o binômio autor-tradutor passou a ser articulada com maior intensidade a partir dos estudos pós-estruturalistas aplicados à tradução - embora a história registre exemplos dessa visão muito antes. Nesse caso, na tentativa de reverter a imagem depreciativa do tradutor, argumenta-se a favor de sua intervenção criativa no texto que produz, assumindo o tradutor o papel de autor ou coautor.

A inescapável presença autoral do tradutor no texto traduzido é ressaltada por Arrojo (1993), que reflete sobre a contribuição do pensamento de Jacques Derrida para a tradução. Em prol da visibilidade do tradutor e da impossibilidade da fidelidade ao texto ou ao autor, Arrojo defende que "alguma forma de violência, alguma forma de parricídio é inerente à atividade do tradutor, que como qualquer leitor, inevitavelmente ocupa um lugar autoral no momento de acionar sua produção de significados a partir do texto de outro" (Arrojo, 1993:82). A intervenção visível na tradução é uma das formas pelas quais o tradutor assume sua responsabilidade autoral e angaria poder para reivindicar reconhecimento social.

Como Arrojo, Sette baseia-se na Psicanálise e na Desconstrução, analisando o desejo do tradutor de ocupar o lugar do autor como uma relação edípica, na qual o tradutor-filho desejaria matar o autor-pai (Sette, 2002:50) para ter acesso ao pres-

TradTerm, 16, 2010, p. 67-95 
tígio da autoria e sublimar seu sentimento de melancolia. Porém, segundo Sette, assim como o filho deve superar o desejo de ocupar o lugar do pai e criar um lugar próprio, o tradutor deve superar o desejo de ser o autor e fundar sua identidade, justamente a partir da diferença em relação ao autor. Assim, a pesquisadora propõe uma terceira forma de abordar a relação autoria-tradução.

O ponto de suporte de sua argumentação é a afirmação de Woodward de que a construção de uma identidade se dá "relativamente a outras identidades (...), isto é, relativamente ao que não é" (Woodward apud Sette, 2002:51). Tal asserção leva Sette a defender que o tradutor não precisa matar o autor para construir uma identidade própria, já que isso implica acabar com a diferença. Assim, ao procurar ocupar o lugar do autor, autodenominando-se autor, coautor ou autor entre aspas, o tradutor apenas expressa um anseio que, longe de lhe oferecer um espaço próprio, o mantém refém do sentimento de impotência e melancolia.

O estudo do discurso de tradutores brasileiros pós-1990 leva Sette a concluir que dentre os textos analisados que fazem menção à imagem do tradutor ou da tradução há o mesmo número de discursos melancólicos e não melancólicos. A essas duas posições, ela acrescenta uma terceira, que mescla traços de identidade melancólica e depreciativa a marcas de certa posição assertiva "pós-moderna". No caso dos resenhistas, são detectadas as mesmas três vozes: a melancólica, a híbrida e a aparentemente associada apenas à pós-modernidade; porém, a voz melancólica apresenta frequência bem menor do que as outras.

Sette apoia-se em Paulo H. Britto, para quem o tradutor deve abrir mão da ideia de autoria e reconhecer que sua escrita é peculiar, pois inclui um elemento único: um texto prévio de um autor. Em outras palavras, é a diferença entre tradução e escrita autoral que garante a identidade da tradução.

\section{A perspectiva histórica: a identidade em movimento}

Os cinco textos que sucintamente comentei acima - a saber, os de Lages (1992), Coracini (2005a; 2005b), Silva (2007) e 
Sette (2002) - convergem em pontos importantes: todos têm por foco tradutores e/ou críticos brasileiros de obras literárias (exceto no caso de Lages), foram redigidos após 1990 e suas conclusões apontam para a predominância ou existência de um tipo de discurso "melancólico", cravado de referências negativas diretas ou indiretas em relação à imagem do tradutor ou da tradução. Suas conclusões possibilitam uma série de conjecturas, que passo agora a tecer, no esforço de elaborar um entendimento que possa contribuir para o debate sobre a configuração identitária do tradutor profissional no Brasil.

Com tal propósito, agrego outra dimensão a respeito do caráter provisório e plural da identidade. Parto da afirmação de Kathryn Woodward (1997), que atribui tal caráter ao fato de que "os processos históricos que, aparentemente, sustentavam a fixação de certas identidades estão entrando em colapso e novas identidades estão sendo forjadas, muitas vezes por meio da luta e da contestação política" (Woodward, 2005:39).

No caso do tradutor brasileiro, suas representações foram sendo forjadas, reiteradas e modificadas ao longo de nossa história, como mostra Pomarico em sua pesquisa de Iniciação Científica intitulada "A identidade do tradutor da perspectiva da História da Tradução no Brasil”, de 2008. Ao analisar os perfis do tradutor desde o período colonial até a década de 70 , Pomarico atribui ao tradutor 12 perfis, a partir de diferentes momentos do contexto histórico, político e cultural brasileiro.

Sua análise é muito interessante e será aqui sucintamente retomada dada sua relevância para nossa discussão e ao fato de ser uma abordagem pouco conhecida.

O primeiro perfil apontado pela pesquisadora é o do tradutor-educador, originado do projeto de tradução de cunho religioso, promovido pela evangelização dos jesuítas. Convive com ele o perfil do tradutor-autor, representado pelos intelectuais que traduziam obras e as apresentavam como se fossem os próprios autores do texto, devido à rigorosa censura por parte da metrópole. Revelam-se aqui os primeiros indícios da invisibilidade do tradutor no contexto político-social brasileiro.

Com a vinda da Corte Portuguesa em 1808, a identidade do tradutor passa por oscilações e contradições. Pomarico, en-

TradTerm, 16, 2010, p. 67-95 
tão, denomina de tradutor-oficial o perfil do tradutor no tempo da Corte, cargo em regime permanente que será, alguns anos mais tarde, eliminado dos documentos oficiais.

Outra imagem é a do tradutor-colaborador, tendo em vista que muitas traduções visavam a agradar membros da Corte e funcionários reais, e os elementos autorais não eram considerados critérios essenciais ao trabalho. Também nesse periodo, os indícios da primeira tradução remunerada sugerem o perfil, ainda embrionário, do tradutor-profissional.

Pomarico prossegue sua análise indicando dois novos perfis que teriam emergido da adoção de costumes europeus no cenário cultural da colônia: os tradutores-romancistas, que trabalhavam para satisfazer os ávidos leitores dos jornais nacionais, divulgando trechos dos romances traduzidos, e os tradutores-dramaturgos, que traduziam, adaptavam e parodiavam grandes clássicos.

As décadas de 30 e 40 do século XX, consideradas a época de ouro da tradução no Brasil, foram marcadas pelo surgimento de editoras exclusivamente brasileiras, nas quais os tradutores selecionados discutiam e partilhavam ideias, criando seus próprios critérios. Emerge, assim, o perfil do tradutor-editor. A ele segue-se o tradutor-escritor, com escritores reconhecidos atuando na tradução de obras e gerando certa visibilidade para o trabalho do tradutor.

O golpe do Estado Novo, em 1937, e a ditadura militar em 1964 impõem o uso da censura em relação aos meios de comunicação, seja por meio do DIP (Departamento de Imprensa e Propaganda), no Estado Novo, ou do Ato Institucional $n^{\circ} 5$, no regime militar. Essas ações levaram os tradutores desses períodos a assumirem o papel de tradutores-auto-censores, como ocorreu com os tradutores do Clube do Livro no Brasil.

De 1940 a1960, o consumo de traduções entre os cidadãos brasileiros aumenta e se intensifica com a política desenvolvimentista do governo, que requer traduções para campos especializados do conhecimento. Para atender essa demanda, o tradutor-especialista passa a trabalhar com textos e documentos de áreas técnicas, incluindo terminologias e jargões.

Nesse ponto de sua análise, Pomarico alerta para a forma como foi construída a identidade do tradutor no Brasil: 
Recapitulando, ao longo da história da atividade tradutória no Brasil, o ofício da tradução sempre esteve vinculado a uma outra profissão, e sua aprendizagem era decorrente da prática e da própria necessidade de produzir a tradução. Somente na metade do século XX passou a haver uma séria preocupação com a regulamentação da profissão e a criação de cursos em nível de graduação. As primeiras reflexões sobre tradução no Brasil só vieram a ser publicadas com o lançamento do livro Escola de Tradutores por Paulo Rónai em 1952. E apenas em 1968 houve a criação do primeiro curso de tradução em nivel superior na PUC do Rio de Janeiro (Wyler, 2003, p. 21). (Pomarico, 2008:26)

A pesquisadora vê, no contexto da fundação da ABRATES (Associação Brasileira de Tradutores), em 1974, uma nova face do tradutor: o tradutor-ativista, que participa como membro de sua associação e reivindica os direitos da profissão.

A inserção de cursos de formação de tradutores em nivel universitário acarreta um novo aspecto, extremamente positivo: o estudo teórico da tradução. Interessados em ampliar seu conhecimento, muitos tradutores educadores dedicam-se à produção de pesquisas. Dessa forma, o tradutor não apenas realiza sua tarefa, mas também reflete sobre o processo e sobre o significado de sua profissão, adquirindo o perfil de tradutor-teórico.

Pomarico conclui que a atual crise de poder do tradutor pode estar relacionada "à negação social e política das reivindicações profissionais do tradutor nos períodos que constituem a história do país, desde seu achamento até o presente" e acrescenta:

Nos limites das fronteiras políticas - que se manifestam em atos burocráticos - e do ponto de vista da dimensão sócio-cultural, o exercício da tradução reveste-se de uma série de estereótipos tanto voltados para a própria ação quanto para o agente em si. As características atribuídas ao tradutor têm origens inegavelmente históricas (...). (Pomarico, 2008:29)

A análise empreendida por Pomarico nos auxilia a compreender muitas colocações associadas à identidade do tradutor

TradTerm, 16, 2010, p. 67-95 
e que foram salientadas nos trabalhos aqui discutidos: invisibilidade, desprestígio social, baixa remuneração, relação ambígua com o autor. Além disso, nos permite perceber que as imagens e os discursos que marcam a identidade desse profissional foram engendrados no panorama histórico e sociocultural de dominação e poder de um país colonizado.

O percurso histórico delineado pela pesquisadora revela as diferentes respostas dadas por aqueles que se encarregavam de traduzir. As várias identidades que o tradutor assume mostram, em sua leitura, uma tendência ao hífen, à vinculação com outro fazer, como se não tivesse sido dado ao tradutor - ou ele não tivesse logrado conquistar - um território próprio.

O ambiente histórico das décadas de 60 e 70 instiga à ação política, e "tradutores-ativistas", como Paulo Ronái, lutam pelo reconhecimento da profissão bem como pela formação universitária. Embora não tenham alcançado todas as metas pretendidas, com a reflexão teórica contribuem para a ampliação da consciência sobre o que é tradução.

Os "tradutores-ativistas" abrem espaço para os "tradutores-teóricos" brasileiros, dentre os quais se destaca Rosemary Arrojo. À luz de ideias pós-estruturalistas, o discurso de Arrojo incita a deslocar a tradução do patamar de inferioridade ao qual era relegada e a rever a identidade do tradutor. Seu tom é visivelmente reivindicador: é preciso marcar a diferença, e ela o faz pelo uso de metáforas que descentralizam o papel do autor e da autoria, por meio de imagens como "texto-palimpsesto" e "tradutor parricida". Nesse momento da história, urge empregar uma linguagem forte, subversora de hierarquias, que inclua aquilo que, por tanto tempo, ficou na e à margem, mesmo que para isso fosse preciso oposição frontal ao autor, ao pai, ao texto original, à palavra cujo significado se pretende imune à negociação. A história mostra que para desafiar um poder instituído as palavras são armas poderosas.

As décadas que se seguem - e das quais dou testemunhopresenciam o gradual fortalecimento da identidade do tradutor, com o aumento lento, mas significativo, da consciência sobre a complexidade da tarefa e o necessário preparo que ela requer por parte daqueles que contratam ou usufruem os serviços de tradução. 


\section{O discurso das empresas e do "mercado": outros retratos}

Mariana Teixeira, em pesquisa de Iniciação Científica recém-concluída (2009), investiga as formas como o tradutor é representado por empresas contratantes de seus serviços e por tradutores egressos de curso universitário com formação em tradução. Seu foco é a identidade do tradutor do ponto de vista da qualificação universitária e do mercado de trabalho. Ela analisa o discurso de 15 sites de empresas que contratam tradutores que trabalham com inglês e português; examina, além disso, questionários respondidos por graduados e graduandos do curso de Letras Inglês/Tradução da PUC-SP, focalizando as imagens do tradutor de textos técnicos. Mesmo levando em conta a função persuasiva da linguagem dos sites e a despeito da pequena amostra de tradutores respondentes, suas conclusões merecem ser consideradas.

A pesquisa indica que nesses contextos o tradutor é visto como um profissional competente, cujo conhecimento é valorizado. Constata, ademais, que, contrariamente à imagem do tradutor literário, como sugerem as pesquisas a respeito, o perfil do tradutor não-literário, ou "técnico", parece mais "otimista":

O tradutor é apresentado como peça-chave do processo, como um profissional importante cujo trabalho nada tem de "automático", apesar de usar ferramentas facilitadoras. Ele é retratado como alguém que toma decisões, cumpre prazos, realiza um trabalho de qualidade, mantém sigilo e trabalha em equipe de forma responsável para satisfazer as demandas do cliente.

O exame das imagens dos profissionais em tradução que atuam nas empresas anunciadas na Internet nos permite concluir que eles são bem vistos, têm uma boa colocação no mercado de trabalho e que as empresas reconhecem sua função intrínseca para o sucesso de seu negócio.

Essas constatações nos levam a afirmar que o profissional ocupa um lugar respeitado no ambiente em que atua. O tradutor é visto como um trabalhador competente e, em momento algum, se percebe a idéia de que seja um profissional com baixa auto-estima ou melancólico. (Teixeira, 2009:31)

TRadTerm, 16, 2010, p. 67-95 
As conclusões da pesquisadora, vinculando um alto nível de especialização à imagem profissional do tradutor, corroboram a percepção de que estamos vivendo uma fase de fortalecimento de sua identidade - percepção essa vislumbrada por Sette no que diz respeito à parcela dos tradutores literários e resenhistas por ela entrevistados.

Porém, a representação que o "outro social" faz do trabalho do tradutor ainda não alcançou a visibilidade e o prestígio das profissões socialmente bem posicionadas. Desse modo, os frutos gestados pela história estão lentamente sendo substituídos por um novo processo de semeadura e maturação.

\section{Considerações finais}

A constelação de traços diferenciais que constitui a identidade do tradutor brasileiro, formada pelo conjunto de imagens diversificadas que tem de si o próprio profissional e que refletem e são refletidas nos fragmentos do discurso do outro, confirmam o caráter fluido, híbrido e provisório (histórico) dessa identidade bem como o fato de que ela está sujeita à ação de diferentes instâncias de poder. Tal constatação endossa o entendimento de que é possivel transformar a imagem do tradutor em prol da visibilidade social da profissão. Lembremos, porém, que tal projeto requer a adoção de um perfil aparentemente unitário e consensual, construído pelo favorecimento e reiteração de determinados atributos.

Afinal, como argumenta Tomás da Silva (2005), o processo de fixar identidades funciona na base da exclusão (sou isso porque não sou aquilo/sou tradutor porque não sou autor) e opera como redução ou esquecimento das semelhanças e complementaridades que atravessam as estruturas sígnicas. A atribuição de determinado sentido a uma identidade profissional dá-se pela criação e reiteração de fatos que, adornados com as devidas pompas discursivas e divulgados por autoridades legitimadas, revestem-se de verdade e credibilidade. A imagem de um profissional depende dos sentidos que o coletivo produz para seu papel social e, com frequência, a definição desse papel implica o seu posicionamento numa hierarquia preexistente partilhada, segundo regras de dominação e subordinação.

TradTerm, 16, 2010, p. 67-95 
Ao refletir a respeito da fixação de identidades étnicas, religiosas ou nacionais com base no critério de "verdade", seja ela biológica ou histórica, Kathryn Woodward lança as seguintes indagações:

\begin{abstract}
É possivel afirmar a identidade étnica ou nacional sem reivindicar uma história que possa ser recuperada para servir de base para uma identidade fixa? Que alternativas existem à estratégia de basear a identidade na certeza essencialista? Será que as identidades são fluidas e mutantes? Vê-las como fluidas e mutantes é compativel com a sustentação de um projeto político? (Woodward, 2005:16, grifos meus)
\end{abstract}

Como vimos, certa dose de "cegueira", ou de "essencialismo", parece mesmo ser útil como base para a estabilização de identidades. Isso quer dizer que, no âmbito da persona social, não é produtivo divulgar as tendências e os interesses múltiplos e paradoxais que residem no interior de uma identidade e que não se sujeitam à lógica do discurso homogêneo e estável. No jogo de afirmação de imagens, nem a variedade nem a fluidez dos discursos que constituem as configurações identitárias devem ser enfatizadas.

No caso do tradutor, seu processo identitário parece ter sido marcado por uma relação ambígua com a figura reconhecida e prestigiosa do autor. Por um lado, dele aproxima-se, submisso, por meio do discurso da fidelidade; por outro, trai seu desejo de ocupar o lugar do autor, manifestando o direito à produção de sentidos e à originalidade. No que concerne ao autor, sua máscara bem adaptada permite-lhe gozar de uma posição de estabilidade no sistema sociocultural brasileiro. O escritor, notadamente o de textos literários, marca fronteiras bem nítidas em relação ao tradutor, cuja posição incerta na hierarquia de produtores de texto parece estar ligada ao poder que exerce a noção de autoria em nossa sociedade ${ }^{3}$.

3 Considerações instigantes e provocativas a respeito da relação entre autor e tradutor podem ser encontradas na tese de doutoramento de M. A G. Antunes $O$ respeito pelo original - uma análise da autotradução a partir do caso de João Ubaldo Ribeiro, PUC-RJ, 2007.

TradTerm, 16, 2010, p. 67-95 
Do ponto de vista da complexidade que constitui a atividade do tradutor e da perspectiva daquele que está no controle do processo tradutório, as questões certamente são outras. Sabemos que a identidade do tradutor tem interface com a de outros profissionais, dentre eles o autor, o crítico, o revisor, o pesquisador, o editor. Na cadeia de semelhanças e diferenças, funções e papéis se sobrepõem, configurando um emaranhado de possibilidades, uma intrincada malha de interações, dentro da qual é difícil delinear contornos nítidos. Entretanto, se o que está em jogo é o fortalecimento da identidade profissional, urge delimitar um espaço social e político por meio da marcação de uma posição visivelmente distinta de outras.

Seguindo esse raciocínio, o fortalecimento do perfil profissional do tradutor no contexto sociopolítico nacional requer a adoção de um discurso centrado em representações positivas. $\mathrm{E}$ para esse fim, não me parece que tem sido oportuna a divulgação, na mídia impressa, de reflexões - sem dúvida legítimas sobre a intimidade do trabalho do tradutor: o embate com as especificidades das línguas e das culturas, as dúvidas e incertezas inerentes ao processo, os equívocos e autocríticas, as perdas inevitáveis, ou mesmo comentários sobre má remuneração e prazos exíguos. Fora do âmbito restrito dos especialistas, o desconhecimento generalizado sobre a natureza dos processos de linguagem e comunicação inviabiliza a compreensão e avaliação de colocações como essas.

Considerando que a voz dos tradutores é uma importante fonte de referência para a formação de sua identidade para além do meio estritamente profissional, acredito que se deve ter cautela quanto à maneira de tornar públicas informações que acabam por reforçar o clichê tradutttore-tradittore ${ }^{4}$, ao se aludir, por exemplo, a problemas de tradução, intraduzibilidade, subjetividade da leitura, interpretação, traição. Retomando Venuti, "dado o conceito dominante de autoria, a tradução provoca o medo da

4 É notável a ironia com que o pensador Jorge L. Borges trata essa imagem do tradutor: "A superstição da inferioridade das traduções - cunhada pelo adágio italiano - procede de uma experiência desatenta" (Borges, 1986:72.). 
92

inautenticidade, da distorção, da contaminação" (Venutti, 2002:65).

A pergunta de Woodward - "Vê-las [as identidades] como fluidas e mutantes é compativel com a sustentação de um projeto politico?" - é muito pertinente. Tudo indica que, no que tange às identidades profissionais, o reconhecimento da permeabilidade das fronteiras entre autor-tradutor não contribui para o fortalecimento identitário, justamente porque essas fronteiras são demarcadas a partir de interesses sociais, politicos e ideológicos particulares.

Enquanto a imagem do autor ou escritor tem sido privilegiada pelos discursos que estruturam e organizam nossa vida cultural, a do tradutor tem sido negativamente valorada. A repetição incansável de um discurso política e socialmente eficaz garantiu para o autor/escritor a fixação de uma identidade que lhe permite usufruir direitos e ter acesso a bens materiais e sociais. Como afirma Silva, "a diferenciação é, [sic] o processo central pelo qual a identidade e a diferença são produzidas" (Silva, 2005:80), o que nos reconduz à década de 80 e aos textos de Arrojo, os quais argumentavam em termos de "parricídio autoral", num esforço de reverter as representações então vigentes, deslocando do centro a figura do autor e tirando da margem a do tradutor.

Creio que é necessário questionar se a referência ao autor, no atual contexto, seja através de aproximação por semelhança ou de negação por diferença, é uma estratégia eficaz para a marcação da posição de identidade do tradutor. Evidentemente, uma questão tão complexa requer muita pesquisa e a inclusão de enfoques múltiplos, contemplando a abrangência dos aspectos implícitos nas definições do papel do tradutor e considerando suas variadas modalidades de atuação.

Possivelmente, o fato de o tradutor trabalhar no espaço entre dois textos, duas línguas, duas culturas, duas subjetividades, entre leitor e autor, torne a delimitação de um território mais dificil ou menos óbvia, fazendo com que sua representação tenda a um ou outro pólo. Porém, é justamente no trânsito "entre" que ele se posiciona como sujeito de um processo ainda pouco conhecido por aqueles que se encontram em posição de poder

TradTerm, 16, 2010, p. 67-95 
para formar opiniões. Sabemos que o tradutor vive da diferença, do intervalo, em plena travessia, e é nessa condição que exerce sua função de facilitador do contato inadiável e fundamental entre nações, comunidades e indivíduos para a integração de conhecimentos e experiências.

Se, conforme indicam muitos estudos sobre a identidade do tradutor, o discurso dos próprios profissionais sinaliza um "débito" em relação ao autor, então é necessário libertá-lo dessa divida e reforçar representações que salientem aspectos pertinentes à tarefa mesma de traduzir. Uma dessas representações é a do mediador intercultural, apresentada por David Katan (2004): ela não se vincula à figura do autor/escritor, privilegia a prática da "facilitação entre" e parece ser um identificador compativel com a função social da tradução e com a plasticidade desse oficio.

O mediador cultural é aquele que facilita a comunicação, o entendimento e a ação entre pessoas ou grupos que possuem línguas e culturas diferentes. O papel do mediador é interpretar as expressões, as intenções, as percepções e as expectativas de um grupo cultural para outro, ou seja, é criar condições que viabilizem a comunicação entre os dois. Para servir como tal elemento de ligação (link), o mediador deve ser capaz de participar de alguma maneira de ambas as culturas. Assim, o mediador deve ser, em alguma medida, bicultural. (Taft apud Katan, 2004:17).

Destaca-se, na citação acima, o papel essencial da interpretação na negociação entre o que se deve e o que se pode dizer nas diferentes línguas, além do fato de que o tradutor trabalha essencialmente com aproximações e leituras, a partir da percepção de sua própria cultura e da do outro. Assim, descrições como essa são importantes como estratégia de reafirmação das especificidades e competências implícitas no exercício da profissão do tradutor.

De todo modo, uma leitura atenta dos múltiplos discursos que definem e descrevem o tradutor já nos permite visualizar transformação significativa na percepção de sua identidade transformação essa ancorada no cenário histórico dos últimos 30 anos. 
Como lembra Woodward, para fixar uma identidade (aparentemente) única e homogênea, no caso para o tradutor, é preciso que ela seja legitimada por instâncias de poder: "a afirmação política das identidades exige alguma forma de autenticação" (Woodward, 2005:25). A colaboração de pesquisadores e teóricos da área de Estudos da Tradução quanto à elucidação do significado da atividade e do papel do tradutor no passado e na atualidade tem propiciado mudanças positivas. A força dessas mudanças pode ser mais abrangente se aqueles que ocupam posições de liderança na vida cultural da nação tomarem para si a responsabilidade de endossar visões informadas sobre a tarefa de traduzir. Trata-se de valorizar o trabalho intelectual daquele que, diante de um texto escrito num idioma, é capaz de traduzilo para outro idioma, para outro ambiente cultural. Uma atividade diferenciada, que apresenta características "incontestavelmente únicas".

Um perfil social coerente e positivo para o tradutor, para além dos parâmetros convencionais de identificação, mostra-se um desafio à altura de nossos representantes legais, educadores, editores, teóricos, críticos e, principalmente, de nossos tradutores.

\section{Referências bibliográficas}

ALBIR, A. H. (2001) Evolución de la Reflexión sobre la Traducción. Traducción y Tradutología. Madrid: Cátedra, pp. 99-132.

ARROJO, R. (1986) Oficina de Tradução. A Teoria na Prática. São Paulo: Ática.

(1993) A tradução passada a limpo e a visibilidade do tradutor. Tradução, Desconstrução e Psicanálise. Rio de Janeiro: Imago,pp. 71-89.

BORGES, J. L. (1986) As versões homéricas. Discussão. São Paulo: Difel, pp. 71-78.

CHNAIDERMAN, M. (2002) Língua(s)-linguagem(ns)-movimento(s): uma abordagem psicanalítica. Lingua(gem) e identidade. Campinas: Mercado das Letras, pp. 47-67.

CORACINI, M. J. (2005a) (Auto-)representações do tradutor: entre a fidelidade e a traição. Tradução e Comunicação. São Paulo: Unibero, n. 14, pp. 91-108.

TRADTerm, 16, 2010, p. 67-95 
(2005b) Discurso sobre tradução: aspectos da configuração identitária do tradutor. TradTerm. São Paulo: Humanitas, vol.11, pp. 29-51.

HALL, S. (2005) A identidade cultural na pós-modernidade. Rio de Janeiro: DP\&A.

KATAN, D. (2004) Translating Cultures. An Introduction for Translators, Interpreters and Mediators. UK: St Jerome Publishing, $2^{\mathrm{a}}$ ed.

LAGES, S. (1992) O tradutor e a melancolia. Trabalhos em Lingüística Aplicada. Campinas: UNICAMP/IEL, n. 19, pp. 91-98.

POMARICO, P. L. (2008) A identidade do tradutor da perspectiva da História da Tradução no Brasil. Pesquisa de Iniciação Científica BIPICCEPE. São Paulo, PUC-SP.

SILVA, T. T. (2005) A produção social da identidade e da diferença. Identidade e diferença. A perspectiva dos estudos culturais. Petrópolis: Vozes, pp. 73-102.

SILVA, J. P. R. (2007) A formação da identidade do tradutor. Pesquisa de Iniciação Científica BIPIC-CEPE. São Paulo, PUC-SP.

SETTE, M. de L. (2002) A identidade (ainda melancólica?) do tradutor uma análise desses profissionais no Brasil na década de 90. Dissertação de Mestrado em Letras e Estudos da Linguagem. Rio de Janeiro: PUC-RJ.

TEIXEIRA, M. B. (2009) A identidade do tradutor: formação universitária e mercado de trabalho. Pesquisa de Iniciação Científica BIPICCNPq. São Paulo, PUC-SP.

VENUTI, L (2002) Autoria. Escândalos da Tradução. Tradução de The Scandals of Translation (1998) por Pelegrin, Villela, Esqueda e Biondo. Bauru: EDUSC, pp. 65-92.

WOODWARD, K. (2005) Identidade e diferença: uma introdução teórica e conceitual. Identidade e Diferença. A perspectiva dos estudos Culturais. Petrópolis: Vozes, Tradução de Tomaz Tadeu da Silva, pp. 7-72. 